\title{
Improved Water Classification Using an Application-oriented Processing of Landsat ETM+ and ALOS PALSAR
}

\author{
Xiaohong Xiao ${ }^{1,2}$, Shimon Wdowinski ${ }^{3}$ and Yonggang $\mathrm{Wu}^{1 *}$ \\ ${ }^{1}$ School of Hydropower and Information Engineering, Huazhong University of \\ Science \& Technology, Wuhan 430074, Hubei, China \\ ${ }^{2}$ School of Mathematics \& Computer Science, Huanggang Normal University, \\ Huanggang 436000, Hubei, China \\ ${ }^{3}$ Division of Marine Geology and Geophysics, University of Miami, 4600 \\ Rickenbacker Causeway, Miami, FL 33149-1098, United States \\ jsjxxh@hgnu.edu.cn,*ygangwu@163.com
}

\begin{abstract}
The aim of this study is to extract water body using the integrated features of Landsat ETM+ and ALOS PALSAR data. Water body extracted from Landsat ETM+ tends to lose smaller water bodies like small rivers and ponds. Besides, water area with plant (lotus) is difficult to recognize. ALOS PALSAR data have a much higher resolution, capable of extracting almost all the water bodies without confusion with other surface features, but leave some holes in water bodies due to its speckles. As a consequence, there is a significant interest in the development of fusion methods that are able to take advantage of the complementary nature of Landsat ETM+ and ALOS PALSAR data. A new combination method of integrating band 3, band 7 of Landsat ETM+ with a modified HH polarization of ALOS PALSAR is proposed, which well combine the complementary water information from each source compared to the standard image fusion methods. Experimental outcomes of the proposed combination B37ModHH shows great enhancement in water classification accuracy compared to Landsat ETM+ and ALOS PALSAR alone.
\end{abstract}

Keywords: Water extraction, remote sensing, Landsat ETM, ALOS PALSAR, image fusion

\section{Introduction}

Fast and accurate extraction of water body is very important for water resources investigation, management, and micro monitoring, wetland protection, lake/coastline change detection, flood prediction and evaluation. This task is difficult, time-consuming, and sometimes impossible for a huge region such as an entire country or continent, when using traditional ground survey techniques [1]. Due to the increasing development of remote sensing technology in recent decades, large amounts of remotely sensed data at a great variety of scales and resolutions have become available for various earth surface observation tasks, which greatly simplifies and facilitates observers' jobs. One of the advantages of remote sensing is that the measurements can be performed from a great distance (several hundred or even several thousand kilometers in the case of satellite sensors), which means that large areas on ground can be covered easily. With satellite instruments it is also possible to observe, a target repeatedly; in some cases every day or even several times per day. The observation of water body from remote sensing images, is of particular importance during these recent years for the following reasons: (i) there is a world-wide important need to assess existing water resource and water resource changes because of the increasing water scarcity and related problems; (ii) the so-called "climate

* Corresponding Author 
change" affects directly and is directly affected by water cycling; (iii) study of water bodies may help to develop water transport route, either by using existing one directly or connecting the existing one by preparing canals to develop a longer water route; (iv) timely information of water increase in hills and mountains may help to develop some strategy to restrict flood calamities [2]. However at the same time, how to evaluate specific datasets to improve our understanding of natural processes and how to investigate the value of complementary data from different sources to provide improved characterizations of land surface phenomena becomes a key problem in remote sensing image processing field. It is increasingly important to understand how data from different sources can be used in a complementary, integrated way to answer specific questions, problems, or issues for a given land surface features and given regions[3]. In year past, there is a great amount of researches on image fusion methods and their advantages in improving information content, spatial resolution or spectral content [4-11], and a large number of articles on the potential of integrating multisource images for improved land cover and land use classification [12-17]. However, less focus has been put on specific ground object extraction. For a specific ground object extraction task, like water extraction, what kind of complementary information is expected to be highlighted and combined from different sources and what kind of a particular fusion method should be adopted for the benefit of the specific task is of great importance.

The aim of this study is to analyze the potential ability of Landsat ETM+ and ALOS PALSAR as complementary information resources in water extraction. As it is known, optical data contains information on the reflective and emissive characteristics of the Earth surface features, while the synthetic aperture radar (SAR) data contains information on the surface roughness, texture and dielectric properties of natural and man-made objects. In years past, the integrated features of these two types of multisource data sets have been efficiently used for an improved land-cover mapping [18-19], forest classification [20-23], and it is evident that a combined use of the optical and SAR images will have a number of advantages because a specific feature which is not seen on the passive sensor image might be seen on the microwave image and vice versa because of the complementary information provided by the two sources [16].

In optical images, as there are multiple bands, and different band combinations will show different appearance and colors for the same feature, it will much easier for people to have more confidence to identify a particular surface class. On the other hand, as different objects in optical images have similar spectral characteristics, water areas tend to be confused with buildings, mountain shadows, cloud shadows, and vegetation as well. Besides, optical data are dependent on weather conditions, suffering from clouds influence, and water areas with plants are difficult to be classified as water. All these become a disadvantage of optical images in water extraction task. While SAR data are irrespective of weather conditions and clouds, sensitive to moisture content, and can interact with underlying structures, which provides potential capability of complementing optical data in water extraction task.

In order to successfully separate water body from non water body, and extract water body as accurate and complete as possible, reliable features derived from both Landsat ETM+ and ALOS PALSAR should be highlighted. The ultimate goal of this paper is to develop an application-oriented method of combining the complementary information from Landsat ETM+ and ALOS PALSAR data together for improved water extraction. Different image fusion methods are compared for integrating Landsat ETM and ALOS PALSAR together for the purpose of water extraction. Finally, a new combination method of integrating band 3, band 7 of Landsat ETM+ with a modified $\mathrm{HH}$ polarization of ALOS PALSAR is proposed, which will combine the complementary water information from each source compared to the standard image fusion methods. 


\section{Study Area and Data}

\subsection{Study Area}

The study area is located in Southeast of Hubei Province with a total size of 157,380 hectares. The study site is characterized by such classes as built-up area, suburban area, farmland area, mountain area, and water area. Hubei has a sub-tropical humid monsoon climate, with high annual rainfall up to $1600 \mathrm{~mm} /$ year and two distinct seasons, namely, a wet season from March to September, and a dry season from October to February of next year. Figure 1(b) shows Landsat ETM+ image dated on 19 August 2008 of the test site, and Figure 2 shows some examples of its land cover classes. The study area has rich water resources, including several lakes, reservoirs, part of Yangtze River, and some small water bodies like rivers and ponds (Figure 1(b)). Around some lakes, especially the northeastern area to Baoan Lake, there is a large area of ponds for fish farming (Figure 2. (a)). In part of Baoan Lake and Huama Lake, there is a large area of lotus planting (Figure 2(c)).

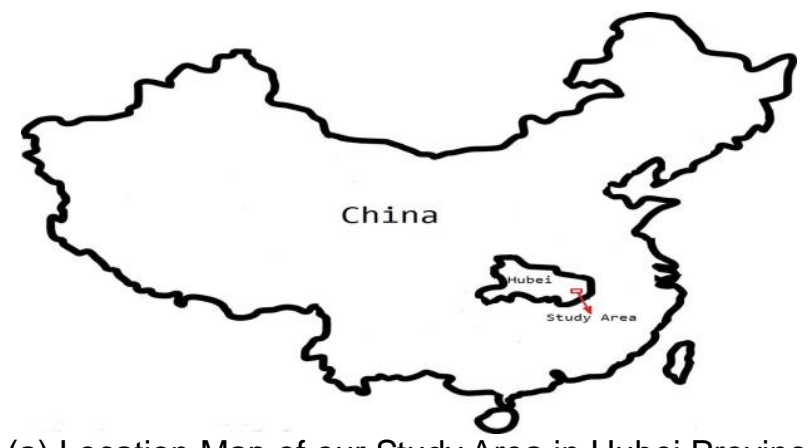

(a) Location Map of our Study Area in Hubei Province, China

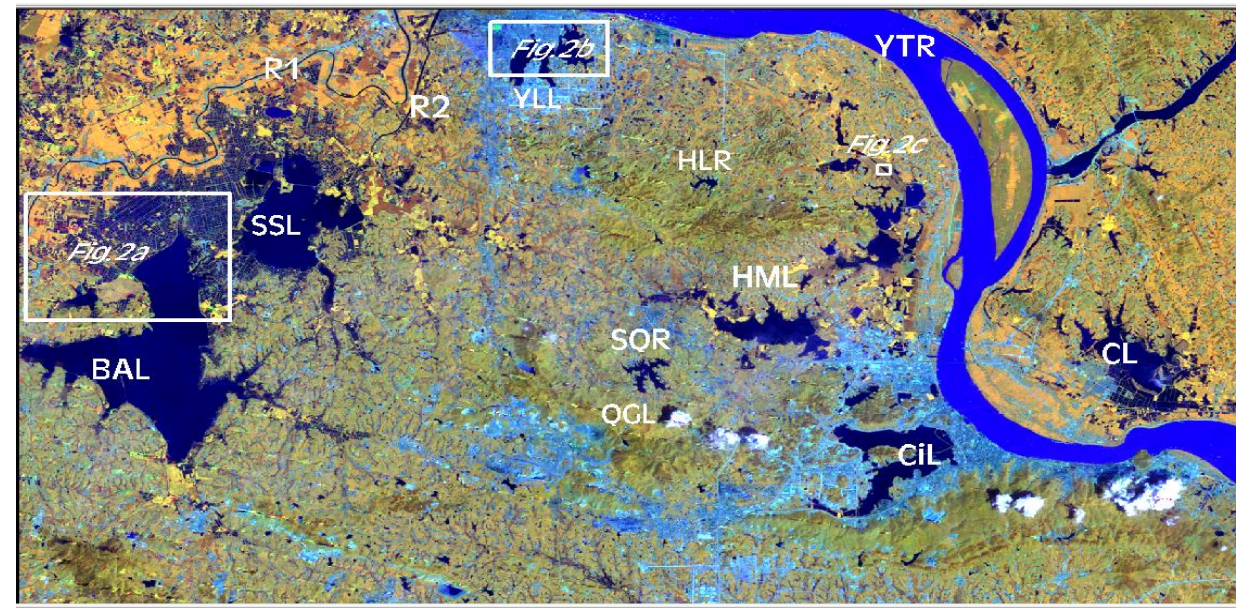

(b) Landsat ETM+ image(band453) of the Study Area

Note: BAL- Baoan Lake QGL-Qinggang Lake CL- Chao Lake HML- Huama Lake HLR- Huanglong Reservoir SQR- Shiqiao Reservoir YTR- Yangtze River R1-small river 1 R2- small river 2

Figure 1. The Study Area 


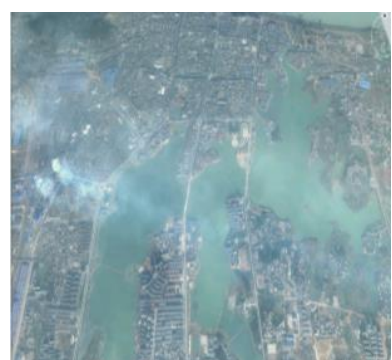

(a)Fish farming area to the North of Baoan Lake

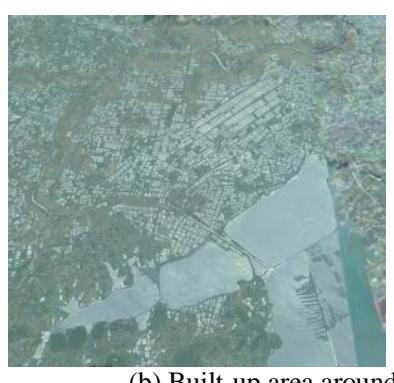

(b) Built-up area around Yanglan Lake

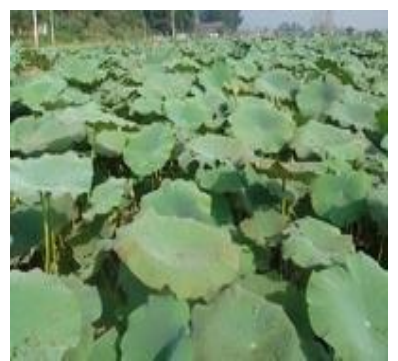

(c) Lotus area of

Huama Lake

Figure 2. Some Land Cover Classes of the Study Site

Note: Figure 2 (a) and (b) are acquired from Google Map; Figure 2 (c) is taken by digital camera on the spot.

\subsection{Data}

(1) Landsat ETM+ data

In the present study, 7 dates Landsat ETM+ images (Path 122, Row 39) have been used, as shown in table 1. The one dated on 20080819 is mainly used in this paper. Others are for comparison and references. Landsat ETM+ image consists of eight spectral bands, with a spatial resolution of 30 meters for bands 1 to 5 and band 7 . The resolution for band $6 \mathrm{H} / 6 \mathrm{~L}$ (thermal infrared) is 60 meters or 30 meters. The resolution for band 8 (panchromatic) is 15 meters. The approximate scene size is $170 \mathrm{~km}$ north-south by 183 km east-west (106 mi by $114 \mathrm{mi}$ ).

In this study, band 1-5 and 7 are used. The thermal band (band 6) was not utilized due to its coarser spatial resolution (approximately 60 meters) and little spectral signature difference between different surface features.

Table 1. Landsat ETM+ Data Specifications (Path/Row: 122/39)

\begin{tabular}{|c|c|c|}
\hline Date & Landsat sensor & Cloud cover(\%) \\
\hline 20080209 & ETM+(SLC-off) & 0.17 \\
\hline 20080515 & ETM+(SLC-off) & 9.63 \\
\hline 20080819 & ETM+(SLC-off) & 5.35 \\
\hline 20090110 & ETM+(SLC-off) & 0.13 \\
\hline 20090907 & ETM+(SLC-off) & 6.97 \\
\hline 20091025 & ETM+(SLC-off) & 0.01 \\
\hline 20100318 & ETM+(SLC-off) & 0.00 \\
\hline
\end{tabular}

(2) ALOS PALSAR Data

ALOS PALSAR data is a Japanese Earth observation satellite carrying a cloud-piercing L-band radar which is designed to acquire fully polarimetric images. The resolution is 12.5 meters. In the present study, the $\mathrm{HH}$ polarization image dated on 20080703 is mainly used, and the other one is used for comparison and reference (Table 2).

Table 2. ALOS PALSAR Data Specifications

\begin{tabular}{|c|c|c|c|c|}
\hline Track/Frame & Date & Mode(Polarization) & Incidence angle & orbit \\
\hline $454 / 590$ & $2007-07-01$ & FBD(HH/HV) & 34.3 & ascending \\
\hline $454 / 590$ & $2008-07-03$ & FBD(HH/HV) & 34.3 & ascending \\
\hline
\end{tabular}

(3) DEM data

A DEM data of the study area with a resolution of $0.0008333 \mathrm{dd}$ has been used for terrain correction of ALOS PALSAR data and for registration with Landsat ETM+ data. 
(4) Ground data

Ground truth information is collected from CMONOC (Crustal Movement Observation Network of China) where GPS points are obtained for classification accuracy assessment.

\section{Methodology}

Figure 3 shows the whole processing framework.

\subsection{Preprocessing of Landsat ETM+ data}

All the Landsat ETM+ data were acquired from http://datamirror.csdb.cn/ with stripes. For each band, the strip was successfully removed by multi image adaptive local regression method (RGF) provided on http://datamirror.csdb.cn/. As can be seen form Table 1, most of the images are covered by cloud which will greatly affect water extraction result. To improve classification accuracy, cloud and cloud shadow should be removed beforehand. In this paper, cloud and cloud shadow were successfully removed using the method proposed by Zhe Zhu [24].

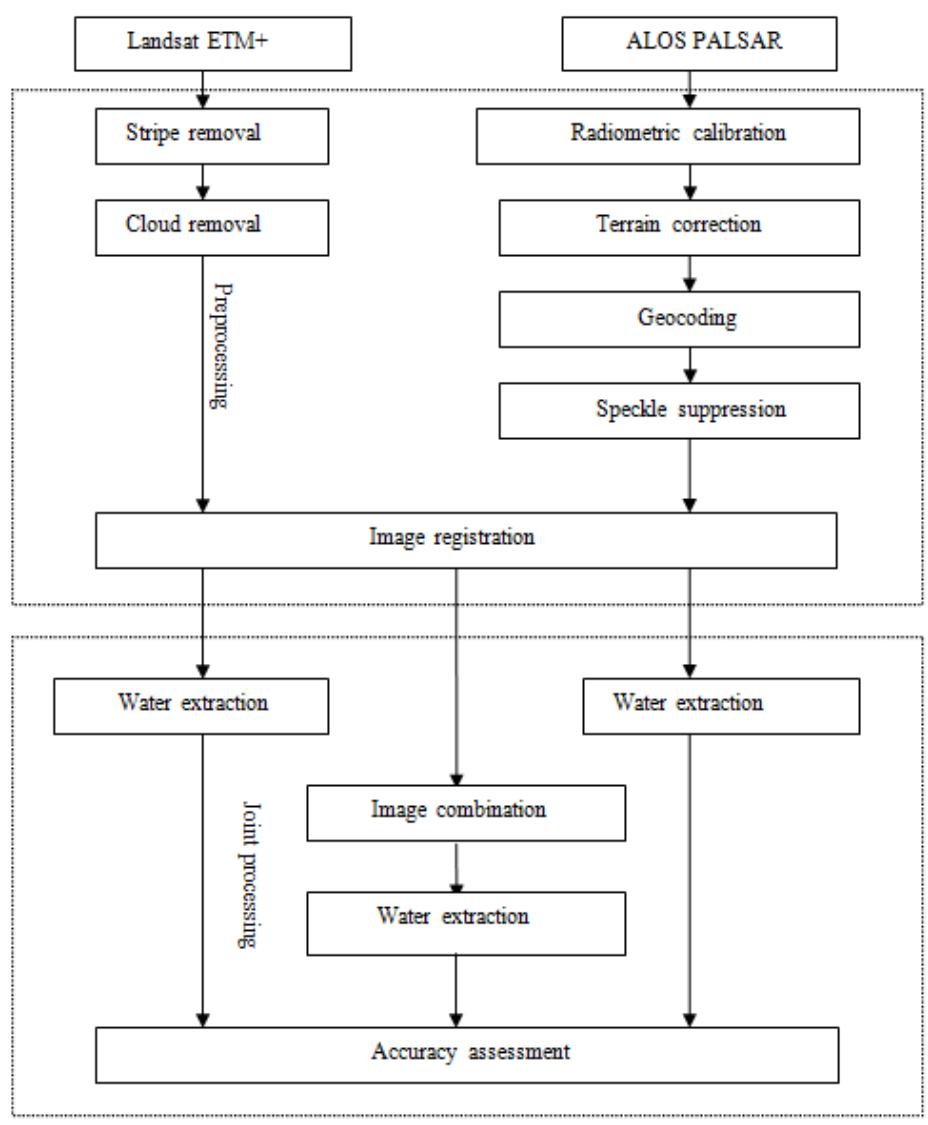

Figure 3. Data Processing Flow of Water Extraction

\subsection{Preprocessing of ALOS PALSAR Images}

The ALOS PALSAR images were provided by Alaska Satellite Facility in level 1.5 format. They were pre-processed independently using ASF MapReady 3.0 software package developed by the Engineering group at the Alaska Satellite Facility. Preprocessing included radiometric calibration using Sigma calibration coefficients, terrain correction based on DEM information, topographic normalization as well as geocoding to $30 \mathrm{~m}$ pixel resolution (WGS84, UTM 50N). 
An obvious disadvantage of ALOS PALSAR image is its speckles which greatly degrades image quality and influence land cover classification and interpretation. Here, a $3 * 3$ local region adapter was adopted to reduce speckles of ALOS PALSAR images.

As Landsat ETM+ and ALOS PALSAR are taken from different sensors, and have different sizes, co-registration is necessary. ALOS PALSAR image was rectified to the coordinates of the Landsat ETM+ image using 12 ground control points (GCPs) defined from a topographic map of the study area. For the transformation, a second-order transformation and nearest-neighbor resampling approach were applied and the related root mean square error was 0.5 pixel.

\subsection{Water Extraction of Landsat ETM+ Images}

A lot of work has been done to extract water body from Landsat ETM + images. Single band threshold and multiband enhancement threshold have been often used in documents to classify water. In 1985, when interpreting the Cairns Section of the Great Barrier Reef Marine Park, through analyzing the histogram of each band of Landsat ETM images, Juppdlb taken the threshold of TM7 to extract water body [25]. In 1990, through experiments, Moller-Jensen set threshold for TM4 and TM5 respectively to classify water area [26]. Lu tried the threshold of TM5 in water classification, but the result is not good [27]. When delineating the Louisiana coastline digital land/water boundary, Brasud and Feng tried threshold for each band to classify water body and evaluated the result, and found TM5 is the most suitable band to adopt for water classification [28]. On the other hand, when detecting Wagga Lake area with Landsat TM data using single band threshold, Frazier and Page found that compared to TM4 and TM7, the threshold of TM5 can achieve higher water extraction accuracy, but failed to extract small water [29]. Single band threshold is very simple. Its basic idea is to observe the spectral feature or the histogram of different classes for each band so as to determine a threshold of a most suitable band. Generally the threshold value should best segment water from non-water body. The disadvantage is that the transition zone between water and non-water is difficult to be determined and some small water body is often neglected.

Multiband enhancement threshold has been mostly used in recent years for water extraction. McFeeter proposed normalized difference water index (NDWI= (TM2-TM4)/ (TM2+TM4)) to restrain vegetation and soil information and successfully extract water body at a high accuracy [30]. Using McFeeter's NDWI, Xu found it is difficult for NDWI to restrain soil and building information in her study case, and proposed Modified NDWI(MNDWI = ( TM2 - TM5) / ( TM2 + TM5)) to extract water [31]. By analyzing the spectral feature of Landsat TM data, Yang found the spectral value of water has the feature that $(\mathrm{TM} 2+\mathrm{TM} 3)>(\mathrm{TM} 4+\mathrm{TM} 5)$, and he extracted water body based on this feature[32]. When identifying plateau and mountain water body, Chen determined a threshold $\mathrm{k}$ for (TM2 + TM3) - (TM4 + TM5) to distinguish mountain shadow from water body, that's, if (TM2 + TM3) - (TM4 + TM5) > k, water body can be extracted with little confusion with mountain shadow[33]. In 2006, for rapid mapping the shoreline changes of five East African rift valley lakes, Ouma Y O and Tathishi R used NDWI3( NDWI3 = ( TM4 - TM5) / ( TM4 + TM5)) and TCW to well determine water boundary [34]. The purpose of multiband enhancement threshold method is to highlight the spectral feature of water so that water can be detected more easily. However, it has two problems. First, with the limit of spatial resolution, some pixels may exist as mixed pixel, which makes it difficult to determine threshold. Higher threshold may result in omission of small water bodies, while lower threshold may result in great confusion and extraction of some nonwater bodies. Second, different methods are dependent on different areas. For example, NDWI may well adapt to non-mountain vegetation area, while MNDWI, TCW, NDWI3 are good for building areas, but difficult in identifying mountain shadows from water bodies. 
In this paper, different methods were tested and compared. The contingency table of different methods for water extraction is shown in Table 3. The definitions of indexes used in this paper are given below.

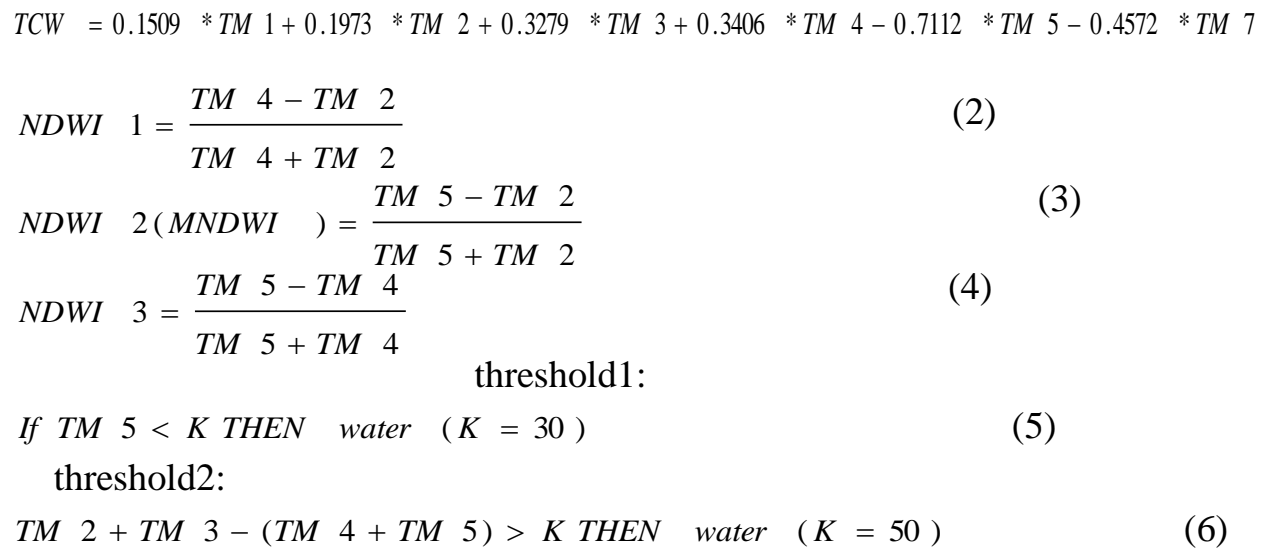

\section{Table 3. The Contingency Table of Different Methods}

\begin{tabular}{|l|l|l|l|}
\hline & & Water(\%) & Non_water(\%) \\
\hline \multirow{2}{*}{ Ndwi1 } & water & 95.75 & 1.46 \\
\cline { 2 - 4 } & Non_water & 4.25 & 98.54 \\
\hline \multirow{2}{*}{ Ndwi2 } & water & 97.93 & 0.83 \\
\cline { 2 - 4 } & Non_water & 2.07 & 99.17 \\
\hline \multirow{2}{*}{ Ndwi3 } & water & 92.66 & 3.25 \\
\cline { 2 - 4 } & Non_water & 7.34 & 96.75 \\
\hline \multirow{3}{*}{ Tcw } & water & 97.04 & 0.53 \\
\cline { 2 - 4 } & Non_water & 2.96 & 99.47 \\
\hline \multirow{2}{*}{ threshold1 } & water & 96.73 & 3.92 \\
\cline { 2 - 4 } & Non_water & 3.21 & 96.08 \\
\hline \multirow{3}{*}{ Threshold2 } & water & 97.35 & 24.51 \\
\cline { 2 - 4 } & Non-water & 2.65 & 75.49 \\
\hline
\end{tabular}

The preliminary water extraction results acquired with Landsat ETM+ images show that as ponds and small rivers are existing as mixed pixels, the spectral signature of them are easily confused with other land cover classes like buildings, vegetation, or mountain shadow. Figure 4 shows the result applying MLC on NDWI1, proposed by McFeeter in 1996 , where water extraction accuracy is $95.75 \%$, but a great confusion between ponds and buildings. Figure 5 displays the result of NDWI2, where water extraction accuracy is 97.93\%, and small rivers can be observed clearly, yet great confusion with buildings and mountain shadows.

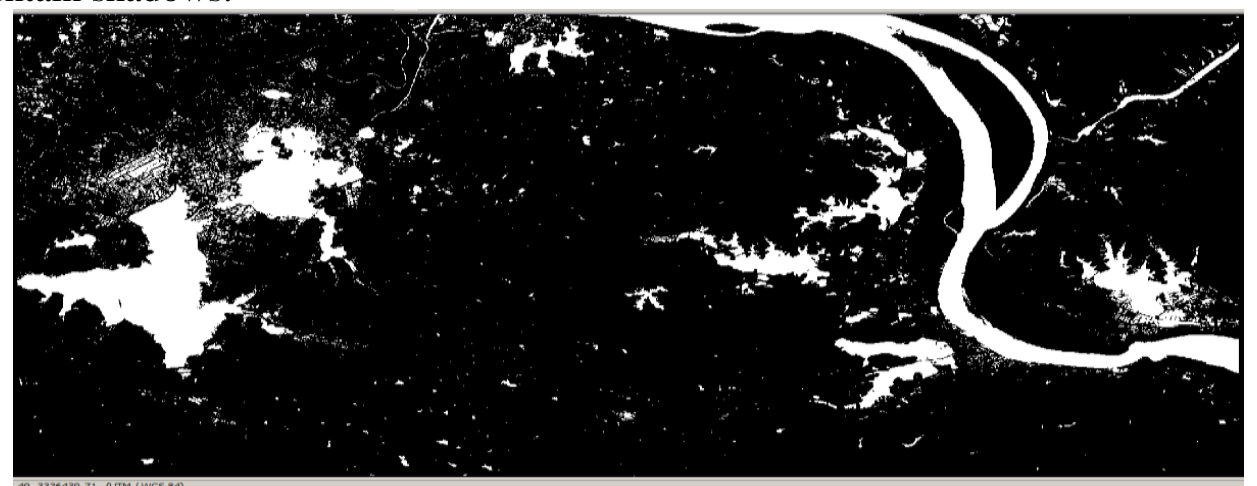

Figure 4. Water Extraction Result of NDWI1 for Landsat ETM+ (20080819) 


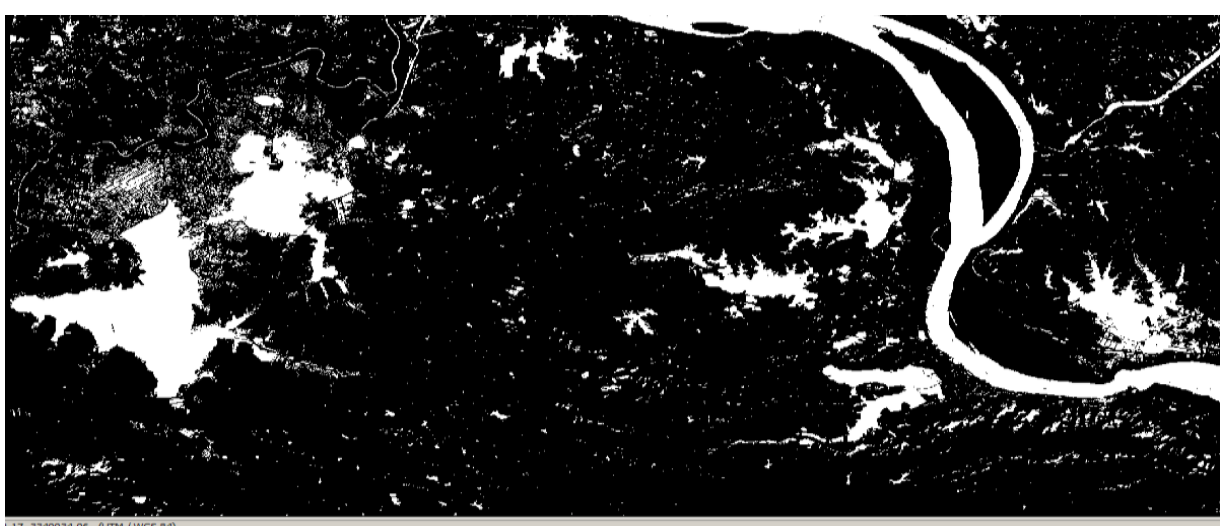

Figure 5. Water Extraction Result of NDWI2 for Landsat ETM+ (20080819)

After comparing the results of NDWIs, we found that even though some of them can obtain high water extraction accuracy, they have different degree of confusion with other classes like buildings, vegetations, and shadows. A way to avoid such confusion is to leave small water bodies like ponds and small rivers behind, that's, to treat small water bodies as non-water body. By doing so, the water body extracted applying MLC for NDWI1 (Figure 6) and NDWI2 (Figure 7) almost has no confusion with other classes, but without doubt, it loses small water bodies like ponds, rivers, and even some reservoirs.

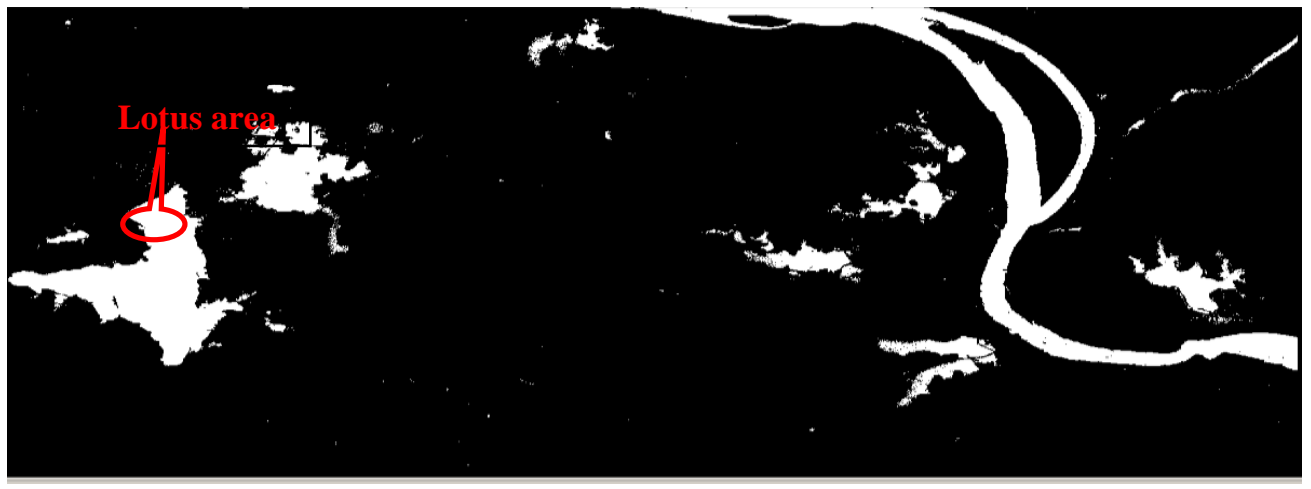

Figure 6. Water Extraction Result of NDWI2 for Landsat ETM+ (20080819) not including Small Water Bodies

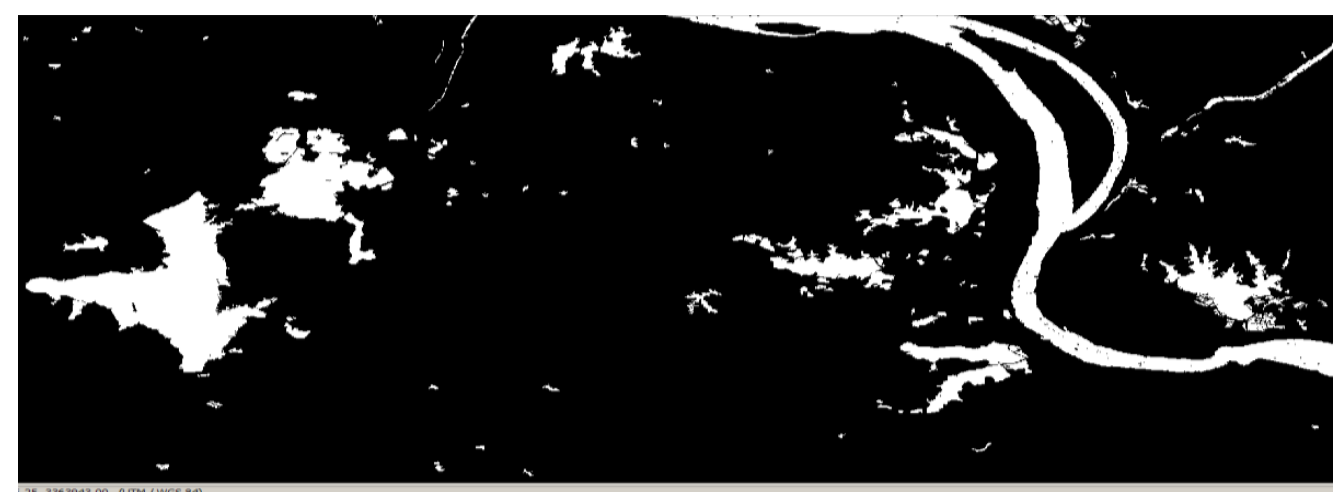

Figure 7. Water Extraction Result of NDWI2 for Landsat ETM+ (20080819) not including Small Water Bodies

Besides, some areas of Baoan Lake and Huama Lake are not classified as water body as there are lotus plants (Figure 6). We observed several images taken at different time respectively, and found that images taken in winter shows complete water there, while in 
summer, no water can be seen. To further identify this area, we came to Baoan Lake and Huama Lake for a field visit. By practical observation and investigation with nearby farmers, we knew that those areas are grown lotus for about 30 years. As summer is the growing period of lotus, winter is its withering period, the water body with lotus cannot be observed from optical images taken in summer, but can be observed through winter optical images.

\subsection{Water Extraction of ALOS PALSAR Images}

The results obtained with the ALOS PALSAR image shows that the finer resolution $(12.5 \mathrm{~m})$ and the dual polarization $(\mathrm{HH}, \mathrm{HV})$ of PALSAR enables the identification of complex and relatively small scale objects such as ponds and small rivers. Furthermore the L-band and multi-polarization mode of PALSAR improved the discrimination of surface and subsurface structures with respect to ETM+ which is not easy to identify water areas with plants. Figure 8 shows the water extraction result of the $\mathrm{HH}$ polarization of ALOS PALSAR on July 03, 2008. As can be seen, small water bodies like ponds and small rivers are extracted, as well as the water area of Baoan Lake and Huama Lake with lotus plants. However, even though ALOS PALSAR can well extract both big water bodies and small ones, due to its speckle nature, some small holes exist in the water area extracted which do not appear in ETM+.

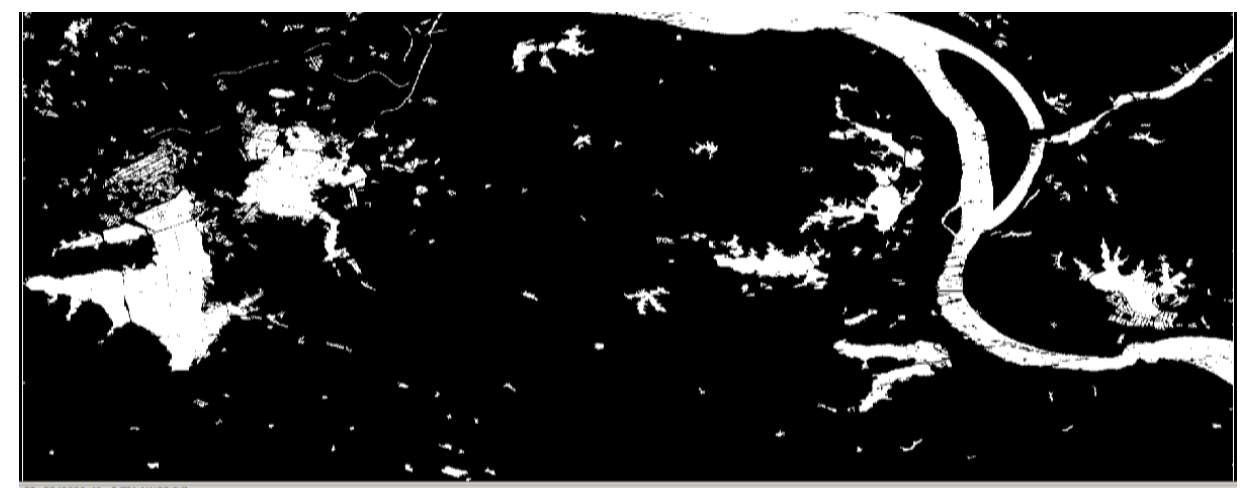

Figure 8. Water Extraction Result of the HH Polarization of ALOS PALSAR (20080703)

\subsection{Image Fusion of ALOS PALSAR and ETM+ Images}

Figure 9 shows the combination of the water extraction results of ALOS PALSAR (20080703) and Landsat ETM+ (20080819). As these two images are from summer and have a short time interval, we can assume that there is no difference between them. The water extracted with ALOS PALSAR is shown in red colour and ETM+ in green colour. This combination can be used as a benchmark as it combines the complementary water information from both Landsat ETM+ and ALOS PALSAR, and thus shows the most complete water areas. Table 4 gives a comparison of water extraction results between Landsat ETM+ and ALOS PALSAR. 


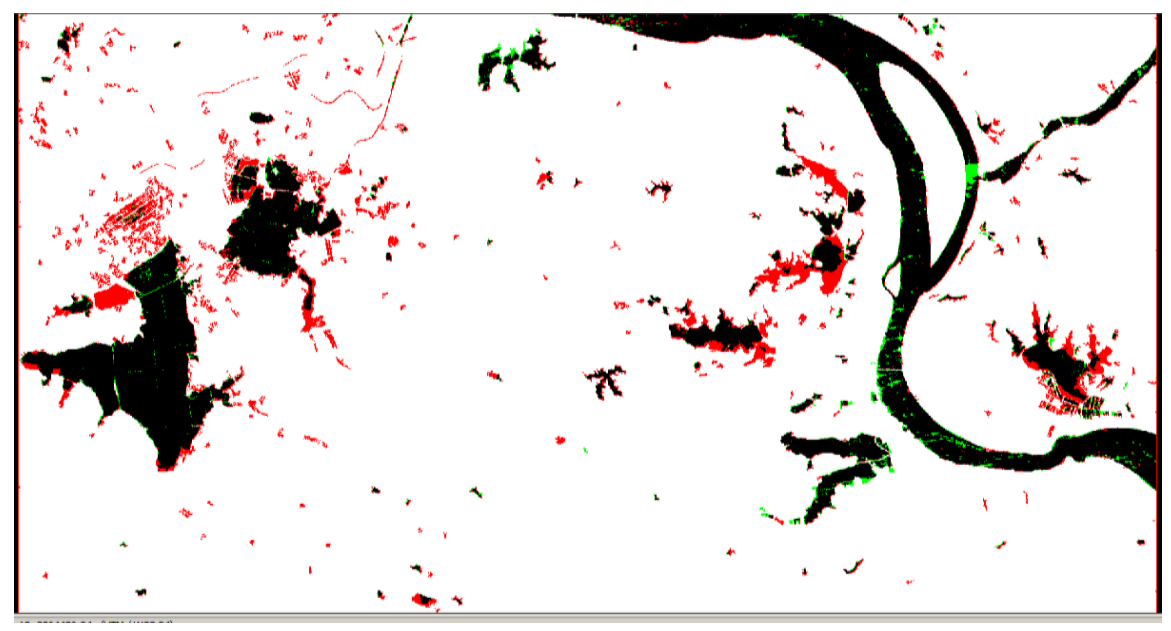

\section{Figure 9. Water Extraction Differences between ALOS PALSAR and Landsat ETM+ (Combination Benchmark)}

As can be seen, ALOS PALSAR extracts more water bodies, especially the ponds to the north of Baoan Lake, two small rivers, and the water area with lotus plants of Baoan Lake and Huama Lake, however, it leaves some holes in Lakes and Yangtze River. As a result, it is significant to combine these two types of images together to take advantage of their complementary information for improved water extraction accuracy. For Landsat ETM+, we want the integrity of large water bodies like lakes and Yangtze River, while for ALOS PALSAR, we want its ability of successfully extracting smaller water bodies like ponds and small rivers, as well as the ability of successfully extracting water bodies with plants.

Different image fusion methods like HIS, PC, HPF, wavelet transform, Brovy transform, as well as different combinations of Landsat ETM+ bands and $\mathrm{HH}, \mathrm{HV}, \mathrm{HH}-$ HV polarization of ALOS PALSAR have been tried. Some of them highlight the information of Landsat ETM+, and some highlight the information of ALOS PALSAR, but none of them can take best advantage of these two data resources. The reason is that ALOS data have very low value for water pixels, and high value for speckle pixels, which is a conflict when fusing into Landsat ETM images. By observing the spectral signature of different band combinations of Landsat ETM+ images, we found that the band with high pixel values will show the primary colour of the resulted combination. The purpose of fusing ALOS into Landsat is to highlight small water bodies and the water area with plants and meanwhile suppress its speckles. Using traditional methods cannot reach this goal. Here we proposed a new combination of Landsat ETM+ image with ALOS HH polarization, which achieved a good result of water extraction.

\section{B3B7MHH Combination}

As there is a conflict between the value of water pixels and speckle pixels in ALOS $\mathrm{HH}$ images, during fusion, if we give more importance to the water value of ALOS, without doubt, we will introduce the speckles into fused images at the same time. As speckles have high values and thus are easy to be identified, a best way to avoid the above conflict is to identify speckles of ALOS HH at the first place, and replace these speckles through interpolation. Then, we reassign the pixel values of HH into 0-255, with the same scale as Landsat images. We stack band 1 to band 5, band 7, and the modified $\mathrm{HH}$ together, and specifically observing the spectral signature of fish farming areas, lotus plant area, and the original speckle areas of HH. To highlight fish farming areas and water areas with plants that appear clearly in $\mathrm{HH}$, the pixel value should higher than that of other selected Landsat bands so that information from HH can take primary role, while 
the value of speckle area pixels of HH should be lower than the selected Landsat bands so that Landsat pixels can replace those speckles in the final image. Aiming at this purpose, we finally found that if we add an additional 20 to each $\mathrm{HH}$ pixel value, and select band 3 and band 7 to integrate with the modified $\mathrm{HH}$ together, the goal can be well achieved. Figure 10 shows the proposed combination image (B3B7MHH), which best integrate the complementary information from both sources, and different water bodies are displayed with different highlighted colour and with little confusion with other land cover classes.

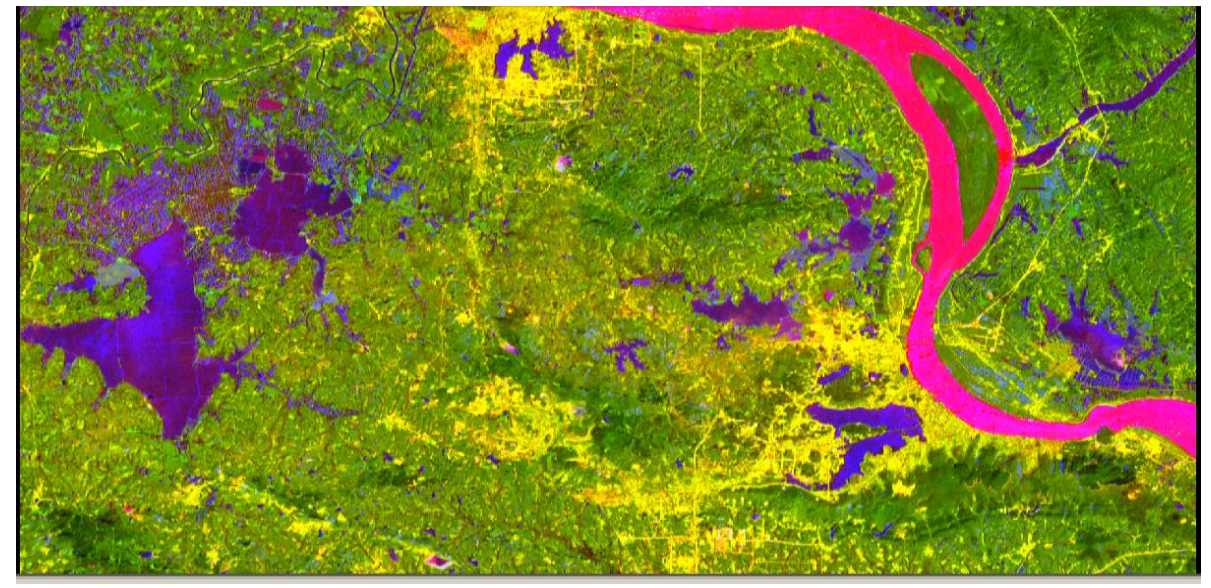

Figure 10. The Proposed Combination of Band 3, band7 of Landsat ETM+ with the Modified HH of ALOS

\section{Results}

Figure 11 displays the water extraction result of the proposed combination B3B $7 \mathrm{MHH}$ using unsupervised classification. Figure 12 compares this result with the combination water extraction result of Landsat and ALOS HH (Figure 9). It shows that the result of the proposed B3B7MHH image has almost the same effect as the combined benchmark. In Table 4, we calculated the percentage of water extracted using Landsat ETM+, ALOS PALSAR HH, and the proposed B3B7MHH. The result shows that the percentage of water extracted of the combination benchmark is the same as that of the proposed B3B7MHH. Table 5 gives the accuracy assessment of this combination, which also shows that the proposed $\mathrm{B} 3 \mathrm{~B} 7 \mathrm{MHH}$ can achieve high water extraction accuracy.

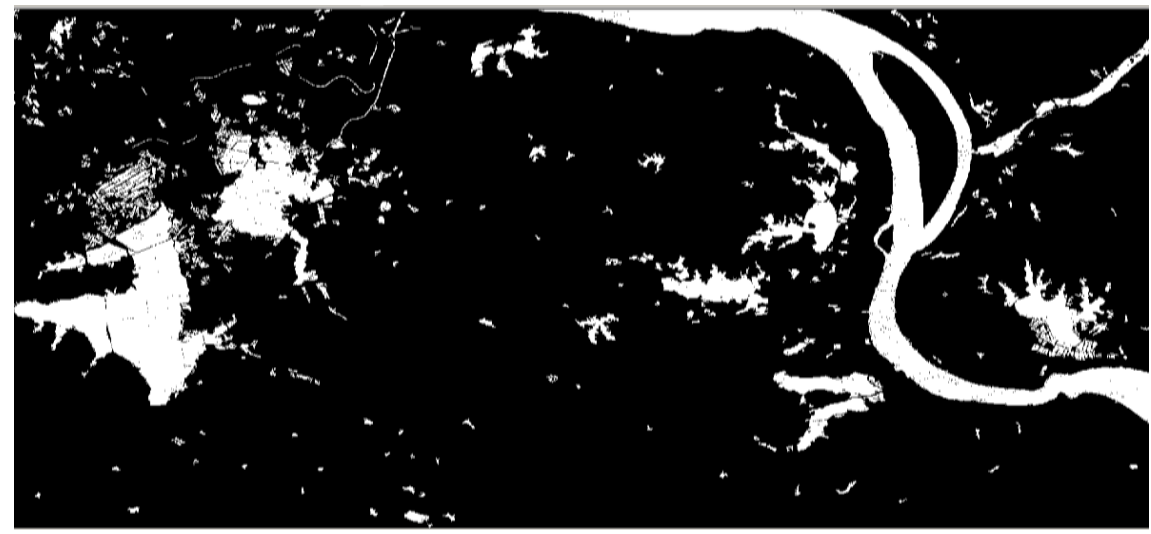

Figure 11. Water Extraction Result of the Proposed Combination (B3B7MHH) 


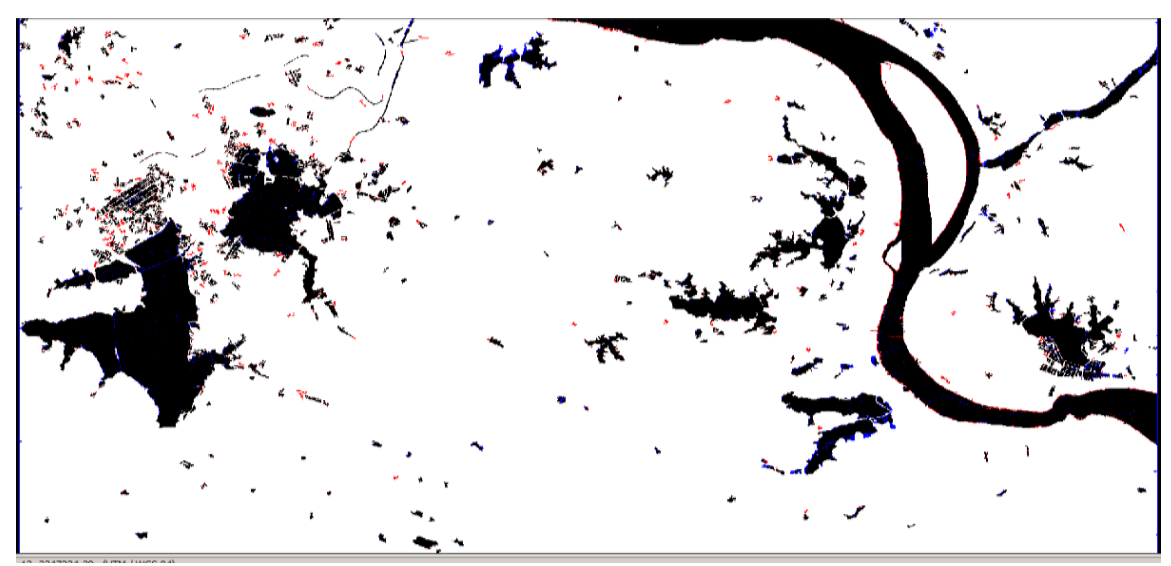

Figure 12. Water Extraction Differences between the Proposed B3B7MHH Combination and the Combination Benchmark

Table 4. Comparison of Water Extraction Results between Landsat ETM+, ALOS PALSAR and the proposed B3B7MHH Combination

\begin{tabular}{|l|c|c|c|}
\hline & color & $\begin{array}{c}\text { Water extracted } \\
\text { Area(ha) }\end{array}$ & $\begin{array}{c}\text { Percentage of total area } \\
(\%)\end{array}$ \\
\hline Landsat ETM+ & green & $15,710.76$ & 9.98 \\
\hline ALOS PALSAR & red & $19,496.34$ & 12.39 \\
\hline Overlapping area & dark & $14,720.22$ & 9.35 \\
\hline Combination water area & & $20,486.88$ & $13.02 \%$ \\
\hline $\begin{array}{l}\text { Proposed B3B7MHH } \\
\text { combination }\end{array}$ & & $20,491.74$ & $13.02 \%$ \\
\hline \begin{tabular}{l} 
Total area \\
\hline
\end{tabular} & & $157,380.57$ & \\
\hline
\end{tabular}

Table 5. The Accuracy Assessment of Water Extraction Result of B3B7MHH

\begin{tabular}{|l|c|c|c|c|}
\hline & water & Non_water & Row total & Users accuracy \\
\hline Water & 354 & 7 & 361 & $98.06 \%$ \\
\hline Non_water & 10 & 829 & 839 & $98.81 \%$ \\
\hline Column total & 364 & 836 & & \\
\hline Producers Accuracy & $97.25 \%$ & $99.16 \%$ & & \\
\hline
\end{tabular}




\begin{tabular}{|l|c|c|c|c|}
\hline $\begin{array}{c}\text { Overall classification } \\
\text { accuracy }\end{array}$ & $98.58 \%$ & & \\
\hline Kappa Statistics & 0.9722 & 0.9627 & $\begin{array}{c}\text { Overall Kappa } \\
\text { Statistics }\end{array}$ & 0.9664 \\
\hline
\end{tabular}

\section{Conclusions}

Landsat ETM+ images have multiple bands, and different band combinations show different aspects of land cover features, which are helpful in identifying a particular land cover type; but as different objects have same spectral signature and different signatures may correspond to same objects, water areas tend to be confused with other land cover types like built-up areas, wet land areas, vegetation, and shadows. Besides, for water areas with plants such as lotus, they will not be easily classified as water body.

ALOS PALSAR data have great advantage in extracting smaller water bodies like ponds and small rivers, as well as water bodies with plants, but they generally have some speckles which destroy the integrity of water body extracted.

Appropriate combination of Landsat ETM bands with ALOS HH image will best fuse the complementary information of both for the purpose of accurate water extraction while suppressing unwanted information.

In this paper, by analyzing the advantages and disadvantages of Landsat ETM+ images and ALOS PALSAR in water extraction, we proposed a new combination method to best merge their useful information for the task of accurate water extraction. And the idea presented in this paper can be used in other classification tasks as well.

\section{Acknowledgements}

This project was funded by Hubei Provincial Education Bureau and Huanggang Normal University jointly. We thank to RSMAS of University of Miami for providing a good experimental environment and Dr. Don Atwood of Alaska Satellite Faculty for providing two sets of ALOS PALSAR data and ASF MapReady 3.0 software for ALOS PALSAR data pre-processing for this project.

\section{References}

[1] S. Bagli and P. Soille, "Morphological Automatic Extraction of Coastline from Pan-European Landsat TM Images", In Proceedings of the Fifth International Symposium on GIS and Computer Cartography for Coastal Zone Management(GISIG and ICCOPS), (2003), pp. 58-59.

[2] R. K. Nath, "S. K. D. Water-Body Area Extraction from High Resolution Satellite Images-An Introduction, Review and Comparison”, International Journal of Image Processing, vol. 3, no. 6, (2010), pp. 20.

[3] E. J. Villiger, "Radar and Multispectral Image Fusion Options for Improved Land Cover Classification", Master Thesis of Science George Mason University, (2008).

[4] M. Ehlers, "Multisensor Image Fusion Techniques in Remote Sensing", ISPRS Journal of Photogrammetry and Remote Sensing", vol. 46, no. 1, (1991), pp.19-30.

[5] C. Pohl and J. L. Van Genderen, "Multisensor Image Fusion in Remote Sensing: Concepts, Methods and Applications", International Journal of Remote Sensing, vol. 19, no. 5, (1998), pp. 823-854.

[6] A. F. G. Simone, F. C. Morabito, S. B. Serpico and L. Bruzzone, "Image Fusion Techniques for Remote Sensing Applications", Information Fusion, vol. 3, no. 1, (2002), pp. 3-15.

[7] P. Pradham and N. Younan, "Concepts of Image Fusion in Remote Sensing Applications", Image fusion: Algorithms and Applications, (2008), pp. 393-428.

[8] G. Pajares and J. M. de la Cruz, "A Wavelet-based Image Fusion Tutorial. Pattern Recognition", vol. 37, no. $9,(\mathbf{2 0 0 4})$, pp. $1855-1872$.

[9] J. Zhang, "Multi-source Remote Sensing Data Fusion: Status and Trends", International Journal of Image and Data Fusion, vol. 1, no. 1, (2010), pp. 5-24.

[10] H. Hariharan and A. Gribok, "Image Fusion and Enhancement via Empirical Mode Decomposition", Journal of Pattern Recognition Research, vol. 1, no.1, (2006), pp. 16-32. 
[11] J. G. Liu, "Smoothing Filter-based Intensity Modulation: A Spectral Preserve Image Fusion Technique for Improving Spatial Details", International Journal of Remote Sensing, vol.21, no.18, (2000), pp. 3461-3472.

[12] C. K. Munechika, J. S. Warnick, C. Salvaggio and J. R. Schott, "Resolution Enhancement of Multispectral Image Data to Improve Classification Accuracy", Photogrammetric Engineering and Remote Sensing, vol. 59, (1993), pp. 67-72.

[13] S. B. Serpico and F. Roli, "Classification of Multisensor Remote Sensing Images by Structural Neural Networks", IEEE Transactions on Geosciences and Remote Sensing, vol. 33, (1995), pp. 562-578.

[14] J. A. Benediktsson, J. R. Sveinsson, P. M. Atkinson and A. Tatnali, "Feature Extraction for Multisource Data Classification with Artificial Neural Networks", International Journal of Remote Sensing, vol.18, (1997), pp. 727-740.

[15] S. L. H. Mascle, A. Quesney, D. Vidal-madjar, O. Taconet, M. Normand and Loumagne, "Land Cover Discrimination from Mutitemporal ERS Images and Multispectral Landsat Images: A Study Case in an Agricultural Area in France”, International Journal of Remote Sensing, vol. 21, (2000), pp. 435-456.

[16] D. Amarsaikhan and T. Douglas, "Data Fusion and Multisource Data Classification", International Journal of Remote Sensing, vol.25, no.17, (2004), pp.3529-3539.

[17] D. Amarsaikhan, M. Ganzorig, P. Ache and H. Blotevogel, "The Integrated Use of Optical and InSAR Data for Urban Land Cover Mapping”, International Journal of Remote Sensing, vol.28, (2007), pp.1161-1171.

[18] D. Amarsaikhan, M. Ganzorig and B. Nergui, "The Combined Application of ALOS PALSAR and Landsat Images for Efficient Land Cover Mapping”, Proceedings of Asian Association on Remote Sensing, (2010).

[19] T. Riedel, C. Thiel, C. Schmullius, "Fusion of Multispectral Optical and SAR Images Towards Operational Land Cover Mapping in Central Europe", Lecture Notes in Geoinformation and Cartography, (2008), pp. 493-511.

[20] N. Gökhan, S. Kasapoğlu, N. Anfinsen and T. Eltoft, "Fusion of Optical and Multifrequency Polsar Data for Forest Classification", IEEE International Geoscience and Remote Sensing Symposium, (2012), pp. 3355-3358.

[21] E. Lehmann, P. Caccetta, Z.-S. Zhou1, A. Mitchell, I. Tapley, A. Milne, A. Held, K. Lowell and S. McNeill, "Forest Discrimination Analysis of Combined Landsat and ALOS-PALSAR Data", in International Symposium for Remote Sensing of the Environment, (2011), pp. 1-5.

[22] E. A. Lehmann, P. A. Caccetta, Z. S. Zhou, S. J. McNeill, X. Wu and A. Mitchell, "Joint Processing of Landsat and ALOS-PALSAR Data for Forest Mapping and Monitoring", Geoscience and Remote Sensing, IEEE Transactions on, vol. 50, no. 1, (2012), pp. 55-67.

[23] W. S. Walker, C. M. Stickler, J. M. Kellndorfer, K. M. Kirsch and D. C. Nepstad, " Large-Area Classification and Mapping of Forest and Land Cover in the Brazilian Amazon: A Comparative Analysis of ALOS/PALSAR and Landsat Data Sources", Selected Topics in Applied Earth Observations and Remote Sensing, IEEE Journal of, vol. 3, no. 4, (2010), pp. 594-604.

[24] Z. Zhu, C. E. Woodcock, "Object-based Cloud and Cloud Shadow Detection in Landsat Imagery", Remote Sensing of Environment, vol. 118, (2012), pp. 83-94.

[25] M. Juppdlb and D. Kuchler, "Landsat Based Interpretation of the Cairns Section of the Great Barrier Reef Marine Park", The C. S. I. R. O. Natural Resources Series, no. 4, C. S. I. R. O, Division of water and land resources, (1985).

[26] L. M. Jensen, "Knowledge-based Classification of an Urban Area Using Texture and Context Information in Landsat TM imagery", Photogrammetric Engineering and Remote Sensing, vol. 56, (1990), pp. 475-479.

[27] L. Jiaju and L. Shihong, "Improvement of Water Identification Technology Using TM", Journal of Remote Sensing, vol. 7, no. 1, (1992), pp. 17-23.

[28] D. H. Brasud and G. W. Fen, "Semi-automated Construction of the Louisiana Coastline Digital Land/Water Boundary Using Landsat Thematic Mapper Satellite Imagery", Louisiana Applied Oil Spill Research and Development Program, OS2 RAPD Technical Report Series, vol. 97, no. 002, (1998).

[29] P. S. Frazier and K. J. Page, "Water Body Detection and Delineation with Landsat TM Data", Photogrammetric Engineering and Remote Sensing, vol. 66, no.1, (2000), pp. 1461-1467.

[30] S. K. McFeeters, "The Use of the Normalized Difference Water Index (NDWI) in the Delineation of Open Water Features", International Journal of Remote Sensing, vol. 17, no. 7, (1996), pp. 1425-1432.

[31] X. Hanqiu, "A Study on Information Extraction of Water Body with the Modified Normalized Difference Water Index (MNDWI)", Journal of Remote Sensing, vol. 9, no. 5, (2005), pp. 589-595.

[32] Y. Cunjian and X. Mei, "Study on Water Extraction Using Remote Sensing Mechanism", Geographical Research, vol. 17, (1998), pp. 86-89.

[33] C. Huafang, W. Jinliang and C. Zhong, "Comparison of Water Extraction Methods in Mountainous Plateau Region from TM Image”, Remote Sensing Technology and application, vol. 19, no. 6, (2004), pp. 479-484.

[34] Y. O. Ouma and R. Tateishi, "A Water Index for Rapid Mapping of Shoreline Changes of Five East African Rift Valley Lakes: an Empirical Analysis Using Landsat TM and ETM+ Data", International Journal of Remote Sensing, vol.27, no. 15-16, (2006), pp. 3153-3181. 


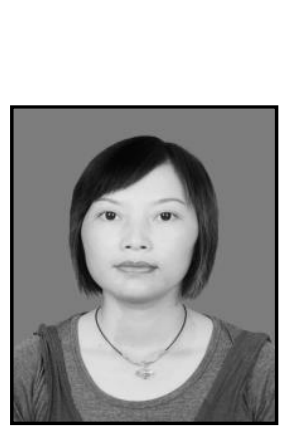

\section{Authors}

Xiaohong Xiao, she was born on 07/14/1975 and from Hubei, China. She received the M.Ei. Degree in Computer technology in 2004 from Wuhan University of Science and Technology in Hubei, China. During 2000-2014, she is a teacher at the school of computer at Huanggang Normal University. Right now, she is pursuing the $\mathrm{Ph} . \mathrm{D}$. degree at School of Hydropower and Information Engineering at Huazhong University of Science \& Technology. Her major is system analysis and integration. Her particular research interests are remote sensing image processing and image fusion for earth observation. In 2013, she had been in RSMAS (Rosenstiel School of Marine and Atmospheric Science) at University of Miami as an exchange scholar for half a year, where she mainly engaged in SAR image processing and image fusion of optical images and Radar Images.

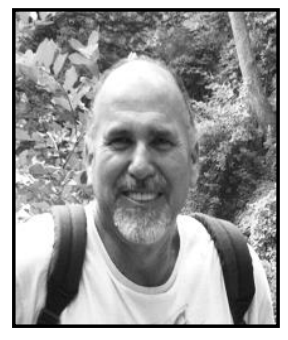

Shimon Wdowinski, he is from Miami, USA. He received a B.Sc in Earth Sciences (1983) and M.Sc. in Geology (1985) from the Hebrew University (Jerusalem, Israel) and an M.S. in Engineering Sciences (1987) and Ph.D. in Geophysics (1990) from Harvard University. He joined the University of Miami in 2001. He is a research associate professor at the Rosenstiel School of Marine and Atmospheric Sciences, University of Miami, where he teaches and researches geology and geophysics. His work has focused on the development and usage of space geodetic techniques that can detect very precisely small movements of the Earth's surface. He successfully applied these technologies to study natural hazards and environmental phenomena, such as earthquakes, landslides, and wetland surface flow.

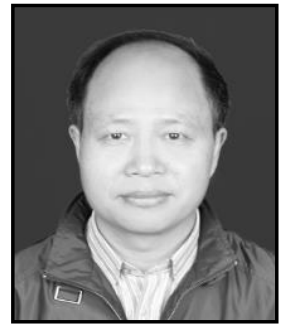

Yonggang Wu, he was boen on 10/27/1963, from Hunan, China. He received the Ph.D. degree in 1997 from Huazhong University of Science and Technology. Currently he is a professor at School of Hydropower and Information Engineering at Huazhong University of Science \& Technology. His main research interests are Generic Algorithm, AGC(Automatic Gain Control), Reservoir Optimized Operation and Control, Water Resources, and Image Recognition. He had been involved in several projects related to the optimization scheduling and AGC of the Three Gorges cascade hydropower station, the Gezhou Dam Er Jiang Power Station, Fujian Reservoirs, and so on. Right now he is holding a Natural Science Foundation of China project related to the AGC of power grid. 
International Journal of Control and Automation Vol. 7, No. 11 (2014) 